\title{
National Variability in Neonatal Resuscitation Practices at the Limit of Viability
}

\author{
Bonnie H. Arzuaga, $\mathrm{MD}^{1} \quad$ William Meadow, $\mathrm{MD}, \mathrm{PhD}^{1}$ \\ 1 Section of Neonatology, Department of Pediatrics, Comer Children's \\ Hospital, University of Chicago Medicine, Chicago, Illinois \\ Address for correspondence Bonnie H. Arzuaga, MD, Wyler Hospital \\ Pavilion, 5839 S Maryland Avenue, MC 6060, Chicago, IL 60637 \\ (e-mail: bharzuaga@uchicago.edu). \\ Am J Perinatol 2014;31:521-528.
}

\begin{abstract}
Keywords

- extremely premature infants

- practice variation

- resuscitation

- physician beliefs

- physician religion
\end{abstract}

Objective Delivery room management of extremely premature infants is not subjected to professional regulations. In the United States, legal definitions of human viability and statutes regulating elective abortions vary by state, placing providers in an often difficult position regarding whether to attempt resuscitation when faced with the delivery of an infant of 22 to 25 weeks gestation. The objective of this study was to delineate variations in delivery room resuscitation practices of periviable infants in the United States in 2012.

Study Design Electronic survey was sent to the members of American Academy of Pediatrics Section of Perinatal Medicine. Chi-square, Fisher exact test, and multivariate logistic regression were performed.

Results A total of 758 surveys returned out of which 637 were complete. Overall $68 \%$ of providers consider 23-week gestation to be the youngest age that should be resuscitated at parental request, while 25 -week gestation is considered by $51 \%$ to be the youngest age of obligatory resuscitation even with parental refusal. Responses varied when providers were separated into geographical regions based on the U.S. Census Bureau $(p<0.05)$. When provided with delivery room scenarios, parental preference significantly affected resuscitation attempts of 22 to 25 weeks, but not 26-week infants. In scenarios of periviable elective terminations, providers' personal belief systems influenced management of aborted fetuses.

Conclusions Regional practice variation exists independent of specific state laws. Parental request is the most important factor to providers resuscitating 22 to 25 -week infants. Providers' personal belief systems influence infant management infrequently.
Delivery room resuscitation practices of extremely premature infants are not regulated by professional associations or legal policy. Instead, physicians are given the right to assess each situation individually and weigh not only the wishes of the parents, but also the initial clinical assessment of the premature infant and their own judgments of medical futility. ${ }^{1-5}$ These factors together dictate the decision of active aggressive resuscitation versus comfort care. Little is known about the criteria used by physicians to make these spur-of-themoment delivery room management plans. Indeed, there is evidence that prenatal counseling decisions do not always correlate with actual delivery room management. ${ }^{6}$ Even less is known about the differences in periviable resuscitation trends among various institutions in the United States. ${ }^{7,8}$

Historically, the social concept of human viability in this country has been closely tied to legislation pertaining to elective termination of pregnancy. In 1973, the landmark case of Roe $v$ Wade made it legal for women to seek a termination from a medical professional. At that time, the United States Supreme Court developed a trimester received

June 7, 2013

accepted after revision

July 23, 2013

published online

September 5, 2013
Copyright $\odot 2014$ by Thieme Medical Publishers, Inc., 333 Seventh Avenue, New York, NY 10001, USA. Tel: +1(212) 584-4662.
DOI http://dx.doi.org/ 10.1055/s-0033-1354566. ISSN 0735-1631. 
framework which permitted abortive procedures after the second trimester only if and when the life or health of the mother was in jeopardy, implying that a fetus became viable at this time. ${ }^{9}$ Almost 20 years later, Planned Parenthood of Southern Pennsylvania $v$ Casey abandoned the trimester model with the opinion of the Court stating, "Whenever viability may occur, be it at 23-24 weeks, the standard at the time, or earlier, as may be the standard sometime in the future, the attainment of viability serves as the critical fact in abortion legislature." 10

Among the 50 states and various territories of the United States, legal definitions of human viability as well as specific statutes regulating termination of pregnancy vary, with some jurisdictions limiting elective abortive procedures to under 19-week gestation and others placing no limits until 24-week gestation or more. ${ }^{11}$ This, in conjunction with the 2002 Born Alive Infants Protection Act (BAIPA), places the pediatrician or neonatologist in an often dubious position regarding whether to attempt resuscitation when faced with the delivery of an infant of 22- to 25-week gestation, classically perceived to be the "gray-zone" of human viability. ${ }^{12}$ Although debatable, ${ }^{13}$ most practitioners try to invoke a "best interests" ethical standard to guide them. However, there are instances when the interests of the parents and the infant may not coincide, ${ }^{14}$ which can make decisions more challenging.

The objective of this study was to delineate any regional variations across the United States in resuscitation practices of periviable infants and to discern whether or not these variations are in concordance with individual state abortion limitation statutes and viability definitions. The study also attempted to ascertain whether physicians' decisions are more greatly influenced by their personal knowledge of laws and policies or instead by their own moral values, religious beliefs, or some other factor.

\section{Methods}

A standard survey was sent electronically via the American Academy of Pediatrics (AAP) to members registered to the AAP Section of Perinatal Medicine in the spring of 2012. Survey questions included demographics of the respondents such as current location of practice, location of neonatal medicine training, years in practice, as well as views on abortion laws, religious affiliations, and knowledge of local legal statutes and definitions. The entire survey is available as supplementary material in the online version of this article.

Initial study questions investigated what youngest gestational age providers would resuscitate if the parents requested and if the parents objected. In addition, respondents were asked what they considered to be the most important factor in delivery room resuscitation decisions, as well as if they had ever been required to either resuscitate or not based on their institution's policy rather than their own clinical judgment.

Subsequent questions assessed the likelihood of delivery room resuscitation given various clinical scenarios. Scenarios varied on gestational age, weight, sex, and initial activity exhibited by the infant, as well as on whether the pregnancy was spontaneous or a product of in vitro fertilization and whether the parents desired the infant to be resuscitated or not. Respondents were asked to rate the likelihood that they would resuscitate the infant in each scenario on a scale of "always," “likely," "unsure," “unlikely," or "never.” Positive responses were considered to be an "always" or "likely" response. An additional scenario examined responses of providers if they were asked to evaluate a fetus after an elective termination of pregnancy for possible viability and to intervene if they believed intervention to be appropriate. Fetuses varied on gestational age ( 22 or $23 \mathrm{wk}$ ), weight and movement or respiratory effort.

Responses were extracted to an Excel database (Microsoft, San Francisco, CA). Chi-square tests, Fisher exact, and multiple logistic regression analysis were done where appropriate using STATA-12 software (StataCorp LP, College Station, TX). Institutional Review Board approval was obtained before the implementation of this study.

\section{Results}

A total of 758 surveys were returned (30\% response rate), of which 637 were complete and used for analysis (-Table $\mathbf{1}$ ). Majority of respondents were attending physicians, had been in practice for at least 10 years and had practiced in their current state of employment for more than 5 years. Almost three-quarters identified themselves as Caucasian, approximately $60 \%$ were Christians, and 68\% considered themselves to be generally prochoice in regards to views on elective termination of pregnancy. The proportion of those who worked in an academic setting versus a community setting was approximately equal. About $70 \%$ of respondents answered that they were both familiar with their local laws limiting abortion as well as their local state definition of human viability.

The first question posed was "what is the youngest gestational age at which practitioners were comfortable attempting full resuscitation, including medications, in the delivery room if the parents requested?" Answers were distributed in a bell curve between 20 and 26 weeks gestational age (-Fig. 1A). The majority (68\%) of respondents felt comfortable at 23 weeks. This did not vary statistically when any demographic variables were controlled for using multivariate logistic regression.

There was statistically significant variation when the country was divided into nine geographical areas based on the United States Census Bureau (-Fig. 2). Overall, 23-week gestational age is generally the youngest that neonatologists are willing to resuscitate in all geographical regions. However, in regards to infants born at 22-week gestation, there is wide variation in practice. Divisions 1 and 9 reported 0 and 5\%, respectively, of respondents willing to attempt resuscitation of a 22-week infant, while Divisions 4 and 8 showed 19 and $23 \%$ of respondents willing to resuscitate at that gestational age, respectively (-Fig. 3A). The differences in these two sets of responses were statistically significant from each other with $p<0.05$. 
Table 1 Measured demographical information of all respondents

\begin{tabular}{|c|c|}
\hline Basic demographics $(n=637)$ & Percent $(n)$ \\
\hline Attending & $91.7(584)$ \\
\hline More than $5 \mathrm{y}$ in current state & $80.8(515)$ \\
\hline More than $10 \mathrm{y}$ of practice & $84.8(540)$ \\
\hline 50 y or older & $58.7(374)$ \\
\hline \multicolumn{2}{|l|}{ Race } \\
\hline Caucasian & $72.8(464)$ \\
\hline African-American & $2(13)$ \\
\hline Asian & $15.5(99)$ \\
\hline Hispanic & $6.3(40)$ \\
\hline Other & $3.3(21)$ \\
\hline \multicolumn{2}{|l|}{ Religion } \\
\hline Catholic & $25.1(160)$ \\
\hline Protestant & $24.5(156)$ \\
\hline Other Christian & $9.9(63)$ \\
\hline Jewish & $12.4(79)$ \\
\hline Muslim & $2.5(16)$ \\
\hline Hindu & $7.4(47)$ \\
\hline Buddhist & $0.3(2)$ \\
\hline Atheist & $5.2(33)$ \\
\hline Agnostic & $8.3(53)$ \\
\hline Other & $4.4(28)$ \\
\hline Active participants in stated religion & $55.7(355)$ \\
\hline \multicolumn{2}{|l|}{ Work setting } \\
\hline Community & $46.8(298)$ \\
\hline Academic & $53.2(339)$ \\
\hline \multicolumn{2}{|l|}{ General abortion opinion } \\
\hline Prochoice & $68.3(435)$ \\
\hline Prolife & $22(140)$ \\
\hline Unsure & $9.7(62)$ \\
\hline $\begin{array}{l}\text { Familiar with legal definition } \\
\text { of human viability in state } \\
\text { of employment }\end{array}$ & $71(452)$ \\
\hline $\begin{array}{l}\text { Familiar with legal limit on } \\
\text { elective termination in state } \\
\text { of employment }\end{array}$ & $68.6(430)$ \\
\hline
\end{tabular}

Abbreviations: $n$, number; $y$, years.

The same analysis was completed in regards to the youngest age in which practitioners would resuscitate an infant, even over parental objection. Overall $51 \%$ answered that 25 week was the cutoff (-Fig. 1B). This also did not change after controlling for demographics.

Again, statistically significant variation based on the geographical location was discovered (-Fig. 3B). The majority of respondents across the country agreed that at 25-weeks infants in most situations should be resuscitated; however Divisions 5 through 7, representing the Deep South and
Texas, have many more practitioners who consider 24 weeks to be obligatory for resuscitation when compared with Divisions 1,8 , and 9 .

When respondents' answers for obligatory resuscitation was compared with state laws regarding specific gestational age limits on elective termination of pregnancy, no correlation was found to exist. In states where a woman is prohibited from obtaining an elective abortion after 23 weeks and 6 days gestation, respondents were paradoxically three-times less likely to consider 24 weeks to be of obligatory resuscitation (12\% of responses) than their counterparts who either practice in a state where a woman can have an elective termination up until 24 weeks and 6 days (36\% of responses) or whose state legislature contained a more vague cutoff of "thirdtrimester" (32\% of responses). This was statistically significant $(p<0.05)$.

In response to the delivery room scenarios, the differences found were similar for all gestational ages between 22 and 25 weeks, with only the overall proportion of respondents attempting resuscitation increasing as the gestational age increased (-Fig. 4). No differences were found in the likelihood of attempted resuscitation based on infant sex or whether the pregnancy was a result of in vitro fertilization. In contrast, weight of the infant significantly affected responses, with bigger infants being more likely to be resuscitated ( $p<0.05$ ). Finally, the most significant difference was seen in what the parents' wishes were. If the parents did not want their baby resuscitated, practitioners were likely to comply $(p<0.05)$. Only at 26 -week gestation did respondents answer that they would always or likely resuscitate the infant over $90 \%$ of the time in all of these scenarios with no differences based on the specific variables. Similar to the previous findings, answers to scenarios did not vary based on the state laws of individual respondents.

The final set of scenarios involved late elective termination of pregnancy procedures and asked the respondents the likelihood of attempting to resuscitate the aborted fetus if they were asked to attend the procedure to evaluate the fetus for potential viability. Overall most providers would not attempt resuscitation in this circumstance for a 22- or 23week fetus, no matter what the weight or whether the fetus exhibited any spontaneous movement or respiratory effort (-Fig. 5A). When divided by self-reported religion, results did not vary significantly with the exception of the $750 \mathrm{~g}$ birth weight 23-week fetus that is moving or having some respiratory effort (-Fig. 5B). One outlying group was illustrated which was Muslims who considered themselves active participants in their religion. The number of people in this category was exceedingly small $(n=11)$ and so whether or not this represents a true phenomenon is unknown at this time.

Whether or not practitioners identified themselves as prochoice or prolife did significantly affect responses in several scenarios (-Fig. 5C). Neonatologists self-described as prolife were significantly more likely to answer that they would "always" or "likely" resuscitate larger, moving or attempting to breathe fetuses following an elective termination of pregnancy when compared with those self-described as prochoice $(p<0.05)$. Similar differences between these 

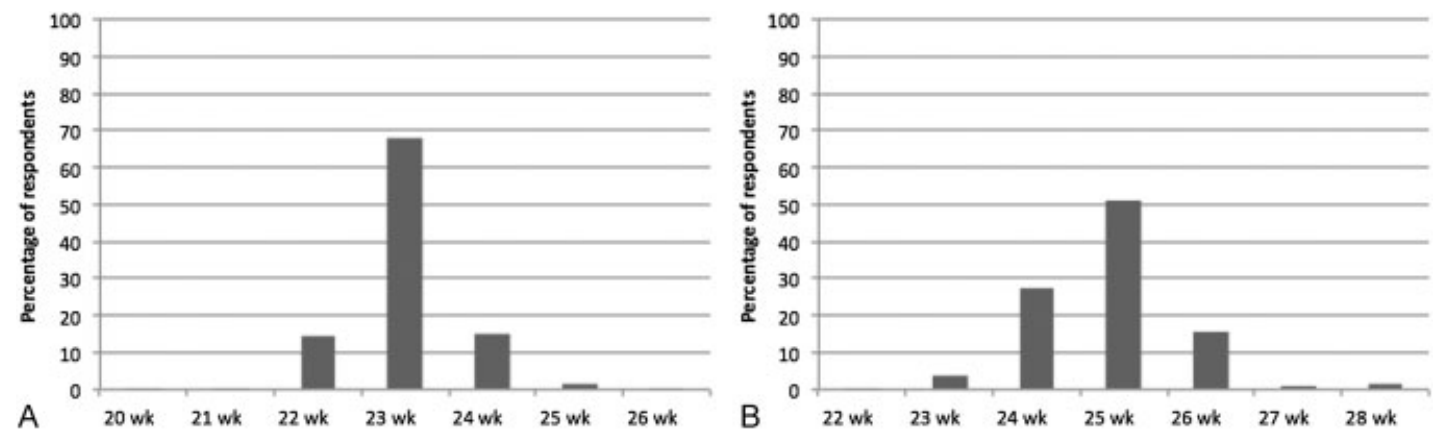

Fig. 1 (A) Youngest gestational age respondents were willing to attempt full resuscitation in the delivery room, including medications, if requested to do so by the parents. (B) Youngest gestational age respondents would always attempt resuscitation, even if the parents objected to them doing so. wk, weeks.

two groups of respondents were not found when responses to the premature labor scenarios were compared even when, in those scenarios, the parents did not wish resuscitation of the premature infant.

Respondents were asked if they had ever resuscitated an infant in objection to their own beliefs because of either their institution's or practice group's policies; $30 \%$ of providers answered yes to this question.

Finally, respondents were asked to rank, in order, factors that they believe influence their decision of whether or not to resuscitate a periviable infant in the delivery room. A total of $33 \%$ of providers ranked parental request as the most important factor. Various categories describing the appearance of the infant in the delivery room, such as infant birth weight, infant respiratory effort, and physical maturity, collectively received $38 \%$ of respondents choosing these as most important.

\section{Discussion}

This is the first study demonstrating geographical variation in current opinions of neonatal providers with regards to peri-

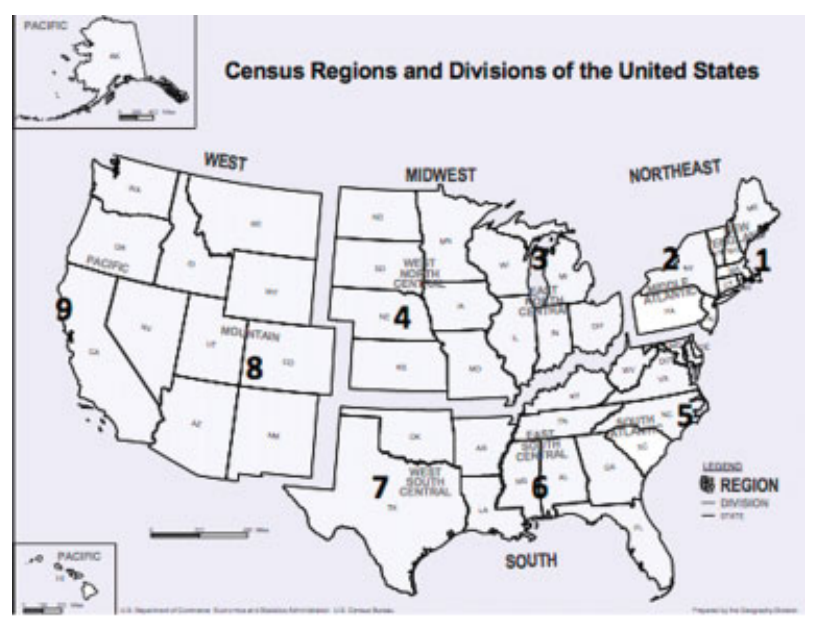

Fig. 2 United States Census Bureau Regional Divisions (2012). Source: https://www.census.gov/geo/maps-data/maps/pdf/reference/ us_regdiv.pdf. viable neonatal resuscitation practices within the United States. While there is a general agreement on resuscitation of infants of 23 weeks being the youngest age that most providers are willing to attempt resuscitation on if the parents want it and 25-weeks being the youngest age that most consider should always be resuscitated even if the parents are opposed to it, the authors found statistically significant regional variation on resuscitation practices of 22-week gestation infants. In addition, the southern region of the United States appears to contain many more providers who believe that infants of 24-week gestation should always be resuscitated, even if the parents are opposed. Interestingly, this variability is not dictated by official state legislature pertaining to limits on elective termination of pregnancy or viability definitions. It also is not dictated by respondent demographics, such as age, religious affiliation or abortion beliefs, as was demonstrated by multivariate logistic regression analysis. Instead practice varies by geographical region, elucidating the possible existence of medical "subcultures" in neonatal practice.

Geographical variation in medical practice is a phenomenon well described in the adult literature in a variety of conditions, from myocardial infarction to breast-cancer treatment and cesarean delivery rates. ${ }^{15-17}$ More general variation in overall physician expenditure has also been described. ${ }^{18}$ Such wide variability fuels the debate over what constitutes usual clinical practice and what can be perceived to be medically appropriate in any given situation. In the case of neonatal resuscitation, what is considered acceptable medical practice has been left to the states and is not consistent, as illustrated in cases such as Miller $v H C A^{19}$ and Montalvo $v$ Borkovecit. ${ }^{20}$ It can be argued that such variation in what is judged to be acceptable can be seen as a violation of the ethical principle of justice when it occurs in the context of life and death decisions of extremely premature infants. There is ambivalence over the innate moral value of a preemie, ${ }^{13}$ which can partly explain why such variability exists. However, why it seems to be geographically based is a harder question to answer and requires further research to tease out underlying themes. Possibilities include how providers are trained, overarching local philosophies, and also access to resources as well as outcomes data. In regards to current 
US Census Bureau Regional Divisions

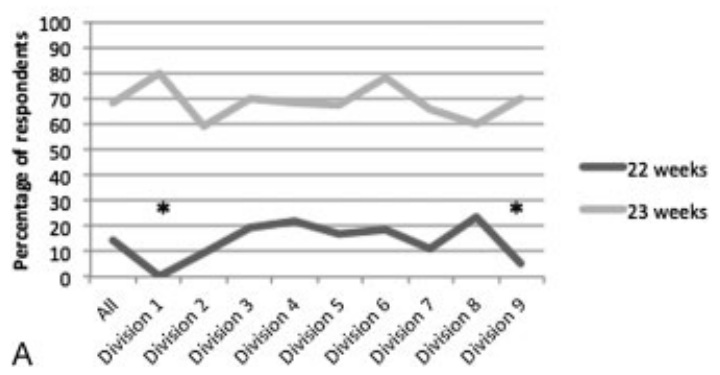

US Census Bureau Regional Divisions

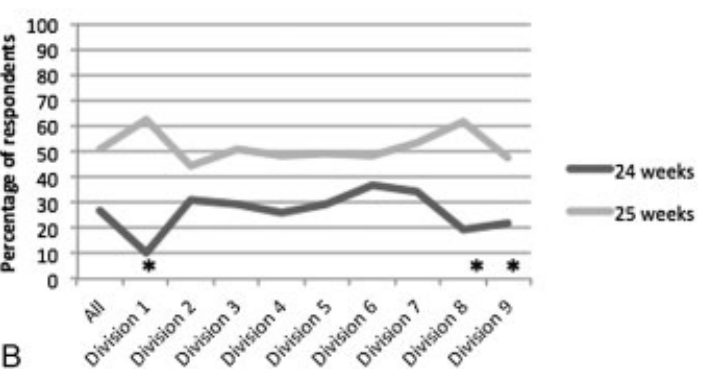

Fig. 3 (A) Youngest age providers would resuscitate at parental request, by geographical location. *, Divisions 1 and 9 significantly less likely to resuscitate a 22-week infant when compared with Divisions 4 and $8(p<0.05)$. (B) Youngest age providers would resuscitate, even over parental objection, by geographical location. * Divisions 1,8 , and 9 significantly less likely to consider 24 -week infants should be resuscitated over parental objection compared with Divisions 5, 6, and $7(p<0.05)$.

22-weeks Gestational Age

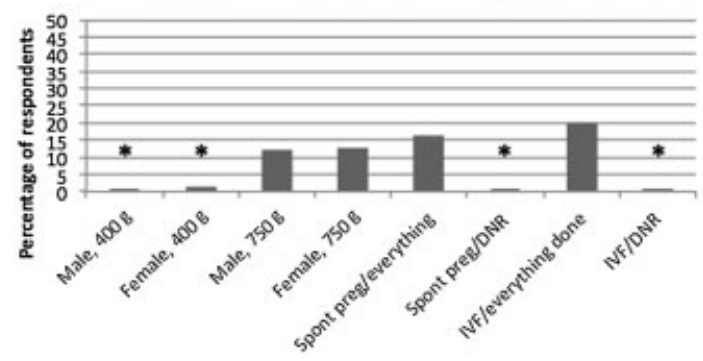

24-weeks Gestational Age

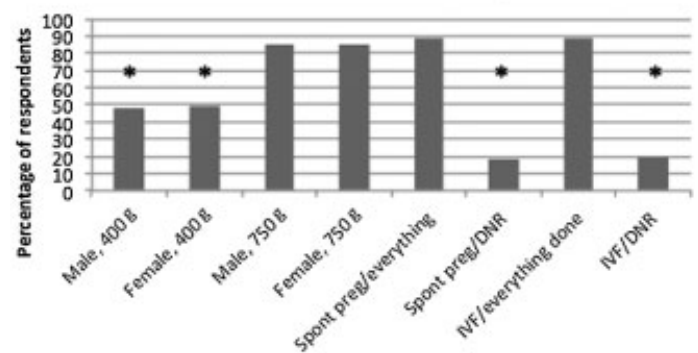

23-weeks Gestational Age

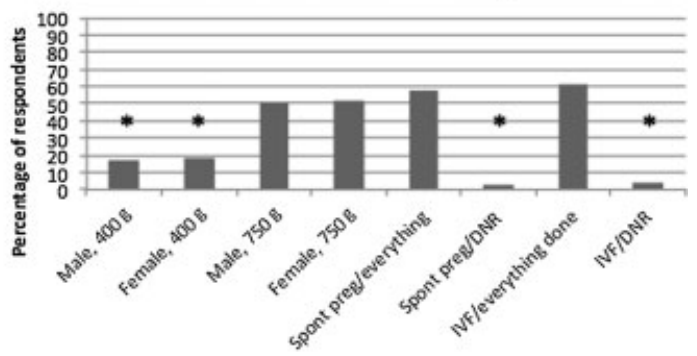

25-weeks Gestational Age

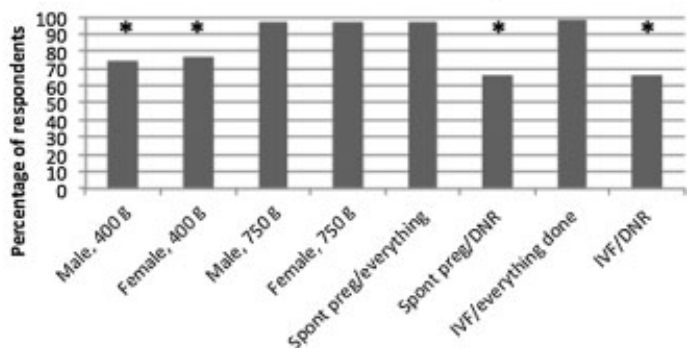

Fig. 4 At 22-weeks to 25-weeks, respondents were less likely to answer "always" or "likely" to attempt resuscitation of smaller infants and infants of parents who do not wish resuscitation. No differences were found in responses based on sex of infants or mode of impregnation. $400 \mathrm{~g}, 400 \mathrm{~g}$ birth weight; $750 \mathrm{~g}, 750 \mathrm{~g}$ birth weight; everything, parents request resuscitation; DNR, parents do not request resuscitation; Spont preg, naturally conceived pregnancy; IVF, in vitro fertilization. ${ }^{*}$ denotes statistical significance $p<0.05$.

survival outcomes, while it may be a factor influencing decisions to attempt resuscitation of extremely premature infants, it must be recognized that this data are affected by aggressiveness of resuscitation as well as providers' willingness to withhold or withdraw medical treatments. Therefore, any scrutiny of statistics related to mortality at the limit of viability should be considered in this context.

The scenario questions illustrate that providers tend to listen to parents and comply with their wishes through 25 -weeks gestational age but not at 26 weeks. When parents' wishes are not known, practitioners tend to use factors relating to how the baby looks to guide their decision-making. The findings based on the scenarios questions were confirmed with $33 \%$ of respondents answering that they consider parental wishes to be the most important factor in the decision to resuscitate in the delivery room and a cumulative response of $38 \%$ specifying that various factors encompassing the idea of "how the baby looks" to be most important. This echoes the findings of previous publications. ${ }^{1}$

Overall 19 states within the United States have laws explicitly stating that a second physician, other than the one doing the procedure, must be present to assess the fetus for potential viability. ${ }^{21}$ These physicians also have the right to intervene and treat the fetus medically if they deem this action to be appropriate. These laws provided the basis for the scenarios describing fetuses of elective termination of pregnancy procedures. The most striking initial result was that $28 \%$ of respondents answered that they would always or likely intervene in the case of a 23-week fetus, $750 \mathrm{~g}$ who is showing some movement or attempts at breathing. When 


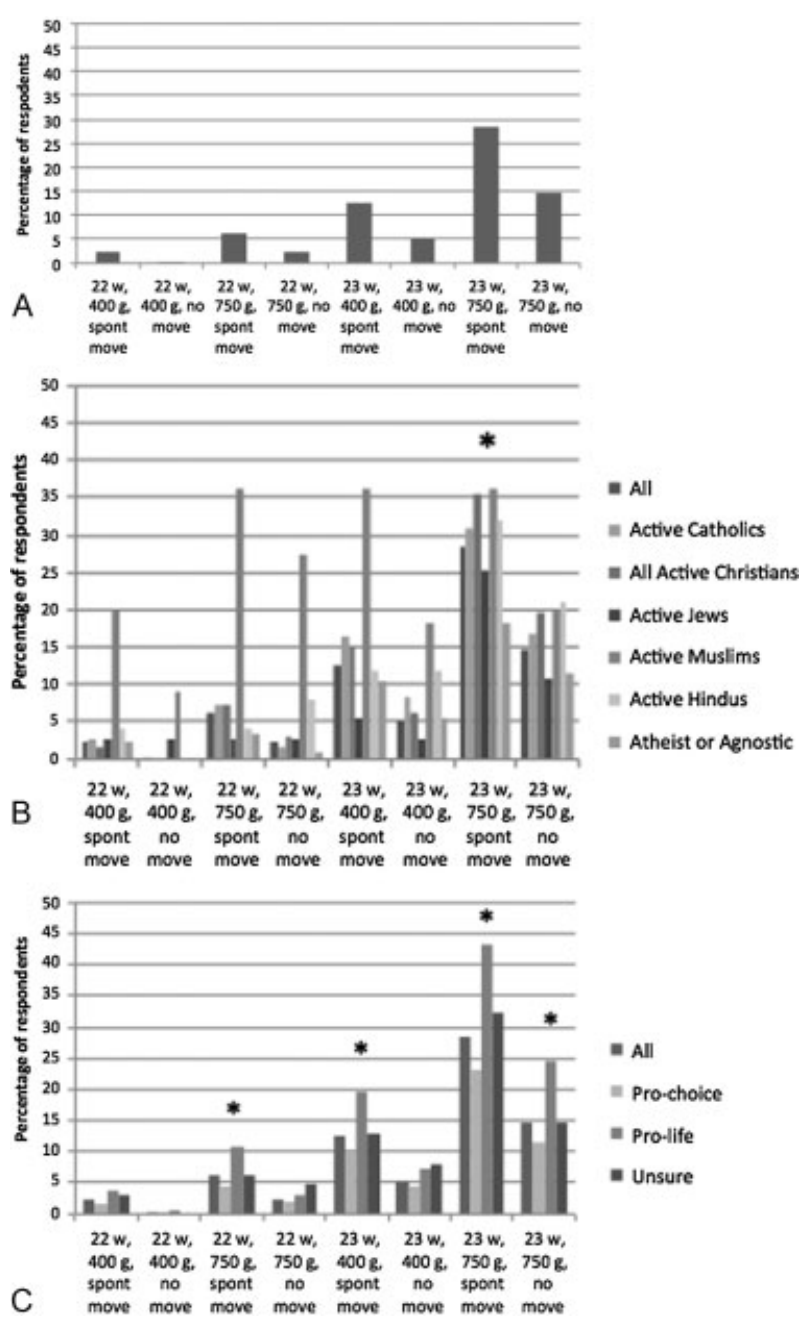

Fig. 5 (A) Respondents answering that they would "always" or "likely" attempt resuscitation on fetuses in scenarios of elective termination of pregnancy procedures where they were required to attend to examine the fetus for potential viability. (B) Responses broken down by selfreported religion. Only respondents who considered themselves "active participants" in their respective religions are shown. (C) Responses by self-reported views on termination of pregnancy. 22w, 22-week gestation; 23w, 23-week gestation; $400 \mathrm{~g}, 400 \mathrm{~g}$ birth weight; $750 \mathrm{~g}$, $750 \mathrm{~g}$ birth weight; spont move, fetus exhibits some spontaneous movement and/or respiratory effort at birth; no move, fetus does not exhibit any spontaneous movement and/or signs of respiratory effort at birth. *, Statistical significance $p<0.05$.

BAIPA was passed by the United States Federal Government in 2002, it stated that any infant born at any stage in development and under any circumstance is considered a "person" with protection of the law. ${ }^{22}$ This Act, although perceived by some to be nothing more than symbolic of antiabortion rhetoric, ${ }^{12}$ has been used in conjunction with the Emergency Medicine Treatment and Labor Act to bring about litigation against physicians and hospitals involved with delivery room management of periviable infants, as was the case in Preston $v$ Meriter Hospital in $2004 .{ }^{23}$ In this case, parents sued the hospital where their 23-week 700-g son was born after premature labor because medical staff did not attempt resuscitation. Although the AAP has issued statements pertaining to how the BAIPA should or should not affect practice, it may still have some influence on delivery room care. ${ }^{24,25}$

In addition, this particular scenario brings up the widely debated concept of providers' rights to conscientious objection. For a fetus to be resuscitated following an elective abortive procedure would constitute a violation of the mother's autonomy, but would protect the moral rights of the infant, being born alive and no longer a part of its mother's body, as a sentient member of the human race. Interestingly, survey respondents who described themselves as "prolife" were significantly more likely to attempt resuscitation on several fetuses after an elective termination of pregnancy when compared with those self-described as "prochoice." When the scenarios describing premature labor were reviewed such variation did not exist between these two particular groups for any gestational age, even when the parents did not desire resuscitation. This leads to the hypothesis that providers' belief systems and/or moral values may play some role in their clinical practice and delivery room management of specific situations.

In contrast, self-reported religious beliefs did not seem to affect most answers in regards to any scenarios. The small number of Muslims whom described themselves as active participants in their religion and took part in this survey were significantly more likely to resuscitate most fetuses as well as smaller infants in the premature labor scenarios when those questions were reviewed again. If this indeed represents a true phenomenon, it would be in concordance with the Islamic concept of human "ensoulment." Although there is some disagreement within the Muslim community, many believe that ensoulment occurs at either 40 or 120 days. Even using the less conservative number, this means that the fetus possesses a "soul" at approximetly17-week gestation, far earlier than any of the periviable situations described in this study. In many Muslim nations, stillbirths after 17-weeks are given proper funerals as any other person would receive, and fetuses have rights and inheritances granted to other members of society. ${ }^{26}$ There has not yet been any research on periviable delivery practice patterns of Muslim physicians in the United States and future studies should focus on determining what these patterns are.

One limitation of this study is that in this setting, hypothetical scenarios can only be answered to delineate a general sense of existing trends. In clinical practice, every case that is encountered by providers contains its own nuances and particulars. A more exhaustive survey could have added innumerable scenarios describing specific physical findings of the infants, such as fused eyelids, skin translucency, etc. Further research is needed to address whether the differences found in the survey scenarios represent actual practice within the United States.

Many ethical debates, such as the moral status of a fetus and a premature infant, as well as the concept of justice in standardizing medical practice across different regions of the US, exist in the field of neonatology. While this study cannot provide answers to these questions, it does provide important 
empirical data to be used as evidence in future discourse. Importantly, while the concept of human viability is constantly evolving, both legal obligations and clinical ethical principles must stay up to date with contemporary medical practice to be the most effective in guiding medical staff in these challenging clinical scenarios.

\section{Conflict of Interest}

The authors declare no conflicts of interest.

\section{References}

1 Singh J, Fanaroff J, Andrews B, et al. Resuscitation in the "gray zone" of viability: determining physician preferences and predicting infant outcomes. Pediatrics 2007;120(3):519-526

2 Kaempf JW, Tomlinson M, Arduza C, et al. Medical staff guidelines for periviability pregnancy counseling and medical treatment of extremely premature infants. Pediatrics 2006;117(1):22-29

3 Partridge JC, Freeman H, Weiss E, Martinez AM. Delivery room resuscitation decisions for extremely low birthweight infants in California. J Perinatol 2001;21(1):27-33

4 Tucker Edmonds B, Fager C, Srinivas S, Lorch S. Racial and ethnic differences in use of intubation for periviable neonates. Pediatrics 2011;127(5):e1120-e1127

5 Hale TM, Arul M, Veerappan A, et al. Predicting survival of periviable fetuses using NICHD fetal heart rate categories. J Perinat Med 2011;39(1):47-50

6 Janvier A, Barrington KJ. The ethics of neonatal resuscitation at the margins of viability: informed consent and outcomes. J Pediatr 2005;147(5):579-585

7 Janvier A, Barrington KJ, Deschênes M, Couture E, Nadeau S, Lantos J. Relationship between site of training and residents' attitudes about neonatal resuscitation. Arch Pediatr Adolesc Med 2008;162(6): 532-537

8 Tucker Edmonds B, Krasny S, Srinivas S, Shea J. Obstetric decisionmaking and counseling at the limits of viability. Am J Obstet Gynecol 2012;206(3):e1-e5

9 Roe v Wade, 410 U.S. 113 (1973)

10 Planned Parenthood of Southern Pennsylvania v Casey (91-744), 505 U.S. 833 (1992)
11 Arzuaga BH, Lee BH. Limits of human viability in the United States: a medicolegal review. Pediatrics 2011;128(6):1047-1052

12 Sayeed SA. Baby doe redux? The Department of Health and Human Services and the Born-Alive Infants Protection Act of 2002: a cautionary note on normative neonatal practice. Pediatrics 2005;116(4):e576-e585

13 Janvier A, Leblanc I, Barrington KJ. The best-interest standard is not applied for neonatal resuscitation decisions. Pediatrics 2008;121 (5):963-969

14 Strong C. The neonatologist's duty to patient and parents. Hastings Cent Rep 1984;14(4):10-16

15 O'Connor GT, Quinton HB, Traven ND, et al. Geographic variation in the treatment of acute myocardial infarction: the Cooperative Cardiovascular Project. JAMA 1999;281(7):627-633

16 Baicker K, Buckles KS, Chandra A. Geographic variation in the appropriate use of cesarean delivery. Health Aff (Millwood) 2006;25(5):w355-w367

17 Farrow DC, Hunt WC, Samet JM. Geographic variation in the treatment of localized breast cancer. N Engl J Med 1992;326 (17):1097-1101

18 Welch WP, Miller ME, Welch HG, Fisher ES, Wennberg JE. Geographic variation in expenditures for physicians' services in the United States. N Engl J Med 1993;328(9):621-627

19 Miller v HCA, Inc, 118 S.W. 3d 758, 771 (Tex. 2003)

20 Montalvo v Borkovec, 647 N.W. 2d 413 (Wis.App. 2002)

21 Guttmacher Institute State Policies in Brief. An Overview of Abortion Laws as of March 8, 2013http://www.guttmacher.org/ statecenter/spibs/spib_OAL.pdf. Accessed March 22, 2013

22 Born Alive Infant Protection Act of 2002 ("BAIPA" Pub.L. 107-207, 116 Stat. 926, enacted August 5, 2002, 1 U.S.C. § 8)

23 Preston v Meriter Hospital, Inc, 2004 WI App 61, 271 Wis. 2d 721, 678 N.W. 2d 347

24 Boyle D, Carlo WA, Goldsmith J, et al; American Academy of Pediatrics Neonatal Resuscitation Program Steering Committee. Born-Alive Infants Protection Act of 2001, Public Law No. 107-207. Pediatrics 2003;111(3):680-681

25 Partridge JC, Sendowski MD, Drey EA, Martinez AM. Resuscitation of likely nonviable newborns: would neonatology practices in California change if the Born-Alive Infants Protection Act were enforced? Pediatrics 2009;123(4):1088-1094

26 Waugh EH. The Islamic Tradition: Religious Beliefs and Healthcare Decisions. Park Ridge Center for the Study of Health, Faith and Ethics, Chicago, IL; 1999 